\title{
Thermal Impact of Reactive Binary Mixture on the Productive Formation
}

\author{
Tatosov A.V., Kutrunov V.N., Antipev V.N., Ivanov A.N., Panchenko N.B.
}

\begin{abstract}
The process of exploitation of an oil producing well leads eventually to the inevitable clogging of the bottom hole zone which significantly reduces the flow rate. A large number of methods for combating accumulated deposits have been developed. One of the most promising and of scientific interest is the method of feeding a reactive energy-releasing binary mixture into the reservoir. The flowing chemical reaction in the zone away from the bottom leads to a significant increase in temperature and, as a consequence, removal of highly viscous fluids and paraffins. In this paper, we propose a mathematical model for feeding a reacting binary mixture into a reservoir. The effects of rock heating and gas evolution are taken into account. An example of the thermal effect on the reservoir is given.

Keywords : Binary mixture, viscosity of oil, oil producing well, drillingmud, mathematical model, drilling fluid density
\end{abstract}

\section{INTRODUCTION}

\section{A. The need of innovation policy for Russian Federation}

Under the conditions of transfer to a digital economy, the competition between is very innovative. The rights of the innovative development path are currently related to Russia, its technological level of the economy is far behind the world market leaders and only occupy the 15th place in terms of scientific research activity [1].

State policy in this field is part of the innovative development strategy of the Russian Federation for the period up to 2020, which was granted rights by Regulation No. 2227-p of the Government of the Russian Federation of December 8, 2011 [2]. Implement the implementation of this strategy as well as Presidential Decree No. 596 of May 7, 2012 "On the general economic policy of the state" until 25\%

Revised Manuscript Received on April 30, 2020.

* Correspondence Author

Tatosov A., Department of Fundamental Mathematics and Mechanics, Institute of Mathematics and Computer Science, Federal State Budget Educational Institution of Higher Education "Tyumen State University" Tyumen State University, Russian Federation. E-mail: atatosov@utmn.ru

Kutrunov V., Department of Fundamental Mathematics and Mechanics, Institute of Mathematics and Computer Science, Federal State Budget Educational Institution of Higher Education "Tyumen State University" Tyumen State University, Russian Federation.

Antipev V., Limited liability company "Energy-2", Russian Federation. E-mail: antipevvn72@mail.ru

Ivanov A., ZAO "SP "MeKaMineft, Megion, Russia. E-mail: aleksey.n.ivanov@gmail.com

Panchenko N.*, Department of Business Informatics and Mathematics, Institute of Service and Industry Management, Federal State Budget Educational Institution of Higher Education "Industrial University of Tyumen”, Tyumen, Russia. E-mail: nbpanchenko@rambler.ru

(C) The Authors. Published by Blue Eyes Intelligence Engineering and Sciences Publication (BEIESP). This is an open access article under the CC BY-NC-ND license (http://creativecommons.org/licenses/by-nc-nd/4.0/) will be tried by 2020 .

The status of intensive scientific products and the energy energy of GDP is $40 \%$. Saving energy in the construction industry is a priority axis of innovation policy. It is used for a

specific energy management of the operation of the built buildings and buildings. For example, for energy efficiency and knowledge perception taken by Presidential Decree No. 899 of June 7, 2011 [4]. The profitable use of resources in connection with the organization of lean production, the management of recyclable materials and the refining of purchases is of equal importance.

\section{B. Negative factors influencing the gas-oil ratio and oil recovery}

The exploitation of oil fields goes with large quantities and extracted petroleum gas (APG), and is heard the development of gas fields and natural gas and gas condensate. Worth noting that APG is valuable resource in both petrochemical and energy industry, but in many cases, it is just flared away. With increasing costs in many countries for excessive APG flaring, oil enterprises are starting to be more rational regards to gas utilization. Therefore, at cluster well drilling for purposes of electrical and heat supply, it is reasonable to use gas-driven power units, fueled by APG extracted from already exploited wells [1].

Due to the breakthrough of gas from the gas cap into the production wells, the actual gas-oil ratio (GOR) is much higher than originally assumed in the field design. The amount of gas generated is close to the maximum re-injection capacity of the high pressure compressors. Capacity limitations affect the amount of oil recovery, which ultimately results in an involuntary restriction on production from the high GOR wells [2].

\section{Influence of temperature and pressure on the drilling fluid density}

When drilling oil and gas wells under the conditions of high reservoir pressure, the multiplication of various complications increases. There is a technique, "forage integrity" refers to the zonal isolation of liquids and gases from the target formation or from the intermediate sofas to pass through passing the forage. Concretely, this means that a well does not leak. Forage companies value the entire car well, repairing a faulty disorder is expensive and rarely costs life, like the Deepwater Horizon disaster in the Gulf of Mexico [3]. To prevent the occurrence of complications during drilling, such as oil, gas and water backflows, cavings and collapses of the wellbore walls and etc., it is necessary to create pressure in the well that exceeds the hydrostatic pressure. 
The primary method of creating the necessary pressure is to increase the density of the drilling mud [4].

Numerous studies show that the temperature and pressure can cause the drilling fluid density changes as follows: low-temperature decreases drilling fluid density; high pressure to produce results in the compression effect increases drilling fluid density $[5,6]$. When designing drilling fluid for deep boreholes and boreholes with better temperature gradients, the weaknesses of the pore pressure and the thermal stress due to the temperature deflection must become. In deep well drilling, if it is protected against the cooling of feed liquid, refusal of the feed well can occur, but also the operation of logging and down hole instruments [7-9].

Main indicators of drilling mud properties (density, viscosity, filtration index, content and composition of the solid phase) depend primarily on the component composition. There is no material for drilling fluids which would solely selectively affect the performance properties of the prepared system. With increase of solid phase content density rises, but the filtration index decreases. Processing of solutions with polymers to decrease the index of filtration is accompanied by increasing of the system viscosity.

\section{METHODOLOGY}

\section{A. Dependence between steaming potential coefficient and demixing temperature}

In practice various methods are used to intensify the production of high-viscosity oil [10,11]. Theoretical and experimental studies of critical binary mixtures near the critical separation temperature Studies of critical binary mixtures near the critical separation temperature are the subject of lively scientific debate [12-15]. It has already been proven that there is no anomaly in the flow potential coefficient when the temperature approaches the segregation temperature. The coefficient of flow potential and the zeta potential decrease with increasing temperature [16]. Vapor equilibrium (VLE) and homogeneous density data are required to develop a reliable equation of state. The two main methods for determining the VLE for mixtures are the analytical method and the synthetic method [17].

\section{B. Abbreviations and Acronyms}

Define abbreviations and acronyms the first time they are used in the text, even after they have been defined in the abstract. Abbreviations such as IEEE, SI, MKS, CGS, sc, dc, and rms do not have to be defined. Do not use abbreviations in the title or heads unless they are unavoidable.

\section{The binary mixture method for the bottom-hole formation study}

One of the most promising and of scientific interest methods is the method of feeding a power-generating binary mixture into the productive formation. It is proposed by Kline, Fogler, Zvyagin and others $[18,19]$ to treat the bottom-hole formation zone with a binary mixture the main component of which is an aqueous solution of two salts sodium nitrite $\left(\mathrm{NaNO}_{2}\right)$ and ammonium nitrate ( $\mathrm{NH}_{4} \mathrm{NO}_{3}$ ). The components of the binary mixture decompose into ions: $\mathrm{NH}_{4}^{+}, \mathrm{Na}^{+}, \mathrm{NO}_{3}^{-}, \mathrm{NO}_{2}^{-}$. After some time, an exothermic reaction of nitrogen and water formation is initiated in the layer under the influence of acid catalysts. As a result of the reaction, the bottom-hole zone is heated and the evolved gas under pressure is dispersed in the formation. After treatment with binary mixtures, the viscosity of the oil decreases, the natural fracturing of the carbonate reservoirs increases [20, 21].

We distinguish mobile phases which differ significantly in properties. Each phase moves at its own rate of filtration, which is common to its constituent components. The first phase includes water and soluble reaction products:

$$
\begin{aligned}
& \mathrm{H}_{2} \mathrm{O}-0, \mathrm{NH}_{4}^{+}-1, \mathrm{Na}^{+}-2, \mathrm{NO}_{3}^{-}-3, \\
& \mathrm{NO}_{2}^{-}-4
\end{aligned}
$$

Its true density is a function of the mass concentrations of the components $\rho_{-} 1=\rho_{-} 1\left(\mathrm{C}_{-} 1 \mathrm{k}\right), \mathrm{k}=0, \ldots, 4$. The second phase is oil; the third is the evolved gas. The porosity of the skeleton $\mathrm{m}$ was assumed to be constant. Each phase is characterized by its saturation $\mathrm{s}_{\mathrm{k}}$, filtration rate $\mathrm{u}_{\mathrm{i}}$, and also by pressures. For a large-scale approximation, a scheme with common p is acceptable. The phase motion obeys Darcy's law [22].

Darcy's law is obeyed under the following conditions:

- the fluid moves slowly, so that the inertia effects can be neglected;

- there is the mass exchange between the phases, but not the momentum exchange;

- the momentum exchange in separate phases associated with the viscous shear is neglected;

- the gravitational force is considered to be an external factor and is applied vertically;

- the viscous displacement obeys Newton's law [23];

- the conditions at the interfaces between the liquid and solid phases correspond to the sticking;

- the solid phase is a perfectly rigid body.

\section{RESULT AND DISCUSSION}

As a result of the chemical reaction, thermal energy is released. In order to simplify the initial system, we assume that the temperature of all phases, including solid rock, is the same and equal to $\mathrm{T}[24,25]$. The feeding model of the reacting binary mixture has the form:

Authors should consider the following points:

$$
\begin{aligned}
& \frac{\partial}{\partial t}\left(m s_{1} C_{1 k} \rho_{i}\right)+\nabla \cdot\left(C_{1 k} \rho_{1} \boldsymbol{u}_{1}\right)=J_{1 k}, \\
& \frac{\partial}{\partial t}\left(m s_{2} \rho_{2}\right)+\nabla \cdot\left(\rho_{2} \boldsymbol{u}_{2}\right)=0, \\
& \frac{\partial}{\partial t}\left(m s_{3} \rho_{3}\right)+\nabla \cdot\left(\rho_{3} \boldsymbol{u}_{3}\right)=J_{3}, \\
& u_{i}=-\frac{k k_{i}}{\mu_{i}} \nabla p_{3} \\
& \frac{\partial}{\partial t}\left[(1-m) c_{0} \rho_{0} T+\sum_{i=1}^{3} m s_{i} \rho_{i} c_{i} T\right]+\nabla \cdot \sum_{i=1}^{3} \rho_{i} c_{i} T u_{i}+\nabla \cdot \sum_{i=1}^{2} p u_{i}=\varkappa \nabla^{2} T+L_{3} J_{3}, \\
& \sum_{i=1}^{3} s_{i}=1, \sum_{k=0}^{C_{1 k}} C_{1 k}=1 .
\end{aligned}
$$

Blue Eyes Intelligence Engineering \& Sciences Publication 
Here $\rho_{i}, e_{i}, h_{i}$ are density, internal energy and enthalpy of phases, including solid rock;

$c_{i}$ is heat capacity of phases; $L_{3}$ is the heat of reaction, referred to the unit mass of the gas formed. The coefficient of thermal conductivity of the medium $x$ is close to the corresponding value for the solid skeleton $x=x_{0}$.

\section{A. Source strength}

In the aqueous solution there is a reaction between nitrite ion and ammonium ion:

In the aqueous solution there is a reaction between nitrite ion and ammonium ion:

$$
\mathrm{NH}_{4}^{+}+\mathrm{NO}_{2}^{-} \rightarrow \mathrm{N}_{2}+2 \mathrm{H}_{2} \mathrm{O} \text {. }
$$

The reaction rate is proportional to molar concentrations (proportions) of the reacting substances. The intensity of the reaction, referred to the unit volume of the first phase is:

$j=k\left[C_{11}\right]\left[C_{14}\right] ;\left[C_{1 k}\right]=\frac{C_{1 k} \rho_{1}}{M_{1 K}}, k=k_{0} \exp \left\{-\frac{E}{R T}\right\} .(4)$

The stoichiometric coefficients of the reaction give the rates of formation of components:

$j_{11}=j_{14}=-j, j_{12}=j_{13}=0, j_{10}=2 j, j_{3}=j$.

For a unit volume of a medium, the rate of mass formation of components is:

where:

$$
\begin{gathered}
l_{1 k}=m s_{1} j_{1 k}, M_{1 k}, J_{3}=m s_{1} j_{3} M_{3} \\
M_{11}=M_{N H_{4}}, M_{12}=M_{N a}, M_{13}=M_{N O_{3}}, \\
M_{14}=M_{N O_{2}}, M_{10}=M_{H_{2} O}, M_{3}=M_{N_{2}}
\end{gathered}
$$

$$
J_{11}+J_{14}+J_{3}=0 \text {. }
$$

Taking into account the initial conditions, the equality of the mole fractions takes place:

$$
\left[C_{11}\right]=\left[C_{14}\right],\left[C_{12}\right]=\left[C_{13}\right]
$$

\section{B. Equations of state}

We take the additively of the specific volumes and heats of the constituents of the aqueous mixture:

$$
\frac{1}{\rho_{1}}=\sum_{k=0}^{4} \frac{c_{1 k}}{\rho_{1 k}}, c_{1}=\sum_{k=0}^{4} C_{1 k} c_{1 k}
$$

Here $\rho_{1 k}$ and $c_{1 k}$ are true densities and heat capacities of the components. The first phase is incompressible $\left(\rho_{1 k}=\right.$ const $)$;

the oil phase is a weakly compressible medium:

$$
\rho_{2}-\rho_{2}^{0}=\frac{p-p_{0}}{a_{2}^{2}}, a_{2}^{2}=\left(\frac{\partial p}{\partial \rho_{2}}\right)_{T}
$$

the nitrogen released during the reaction obeys the equation of state of an ideal gas:

$$
\rho_{3}=\frac{p M_{3}}{R T} .
$$

The heat of reaction $L$, per unit mass of the initial dry binary mixture, is related to $L_{3}$ by the relation:

$$
L \sum_{k=1}^{4} M_{1 k}=L_{3} M_{3} \text {. }
$$

\section{Filtration parameters}

Relative phase permeabilities are given in the form:

$$
k_{1}=s_{1}^{2}, k_{3}=s_{3}^{2}, k_{2}=\frac{s_{1}\left(1-s_{1}\right)^{2}+s_{g}\left(1-s_{g}\right)^{2}}{s_{1}+s_{g}} \text {. }
$$

Heating the formation significantly changes the viscosity of oil:

$$
\mu_{2}=\mu_{20} \exp \left\{k_{\mu}\left(\frac{1}{T}-\frac{1}{T_{\mathrm{n}}}\right)\right\}
$$

The viscosities of gas and water can be considered constant

\section{$\mu_{1}, \mu_{3}=$ const}

\section{Initial and boundary conditions}

In an axisymmetric formulation:

$$
u=u e_{r}, \nabla=\frac{\partial}{\partial r} e_{r}, \nabla \cdot=\frac{1}{r} \frac{\partial}{\partial r}\left(r \frac{\partial}{\partial r}\right) e_{r}
$$

Initial and boundary conditions for equations of motion with unknowns:

$$
\begin{aligned}
& p=p(r, t), T=T(r, t), s_{i}=s_{i}(r, t), C_{1 k}= \\
& C_{1 k}(r, t), r_{w} \leq r \leq r_{e}, t \geq 0
\end{aligned}
$$

have the next form:

$$
\begin{gathered}
t=0 ; \quad p=p_{0}, T=T_{0}, s_{i}=s_{i}^{0}, C_{1 k}=C_{1 k}^{0} ; \\
0<t \leq \tau, r=r_{w} ; \frac{\partial p}{\partial r}=p_{w}^{r}, T=T_{0}, s_{i}=s_{i}^{w}, C_{1 k}=C_{1 k}^{w} ; \\
t>\tau, r=r_{w} ; \frac{\partial p}{\partial r}=\frac{\partial T}{\partial r}=0 ; \\
r=r_{e}: p=p_{0}, \quad T=T_{0}
\end{gathered}
$$

The reaction starts at $t=\tau_{r}$.

During the time $\tau$ an aqueous solution of chemically active components of a given composition is injected, the reaction can be frozen at the same time. The molar proportions of the components are the same. The $C_{1 k}$ values on the power supply circuit are expressed in terms of the total mass content of the feed mixture $C_{m \text { : }}$

$$
C_{1 m}^{w}=\frac{M_{1 i}}{\sum_{k=1}^{4} M_{1 k}} C_{m}, C_{m}=\sum_{i=1}^{4} C_{1 i}=1-C_{10}
$$

The aqueous mixture comes with a constant injectivity $\mathrm{Q}$ (volumetric flow):

$$
\frac{\partial p}{\partial r}\left(r=r_{w}\right)=\frac{\mu_{1} Q}{2 \pi k r_{W} H}
$$

$H$ is the thickness of the formation. In this case, the mass flow of the binary mixture is:

$$
Q_{m}=C_{m} \rho_{1} Q
$$

The well is then closed before the end of the chemical reaction in the formation.

Reservoir pressure and temperature values:

$p_{0}=100 \mathrm{bar}, T_{0}=300 \mathrm{~K}$;

The pore space is filled with oil: $s_{1}=0, s_{2}=1, s_{3}=0$, $C_{1 k}^{\circ}=0$;

Porosity is $m=0.2$, formation permeability is $k=100 \mathrm{mD}$;

Heat capacity and thermal conductivity of the rock $c_{0}=1000 \mathrm{~kJ} / \mathrm{kg}, x=1.8 \mathrm{~W} /(\mathrm{m} \cdot \mathrm{K})$;

The viscosity of oil is $\mu_{20}=100 \mathrm{cPs}$;

The reacting binary mixture is supplied with a constant mass flow rate $Q_{m}$ and a specified content $C_{m}$;

On the discharge circuit: $s_{1}^{W}=1, s_{2}^{W}=0, s_{3}^{W}=0$, $C_{1 k}=C_{1 m}^{w}$

The reaction is not frozen $\tau_{r}=0$, the well is closed when the formation temperature in the reservoir is $373 \mathrm{~K}$;

The reaction constants are $k_{0}=5.9 \cdot 10^{9} \mathrm{~m}^{3} /(\mathrm{mol} \cdot \mathrm{s})$, $E=77 \mathrm{~kJ}, L=300 \mathrm{~kJ} / \mathrm{mol}$.

In numerical simulation it has been established that the time

Published By:

Blue Eyes Intelligence Engineering \& Sciences Publication

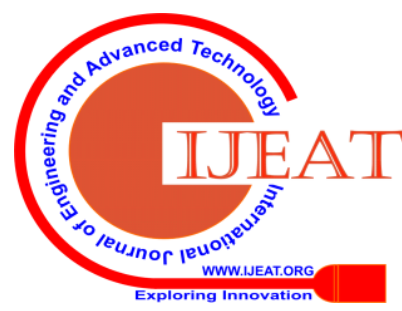


$\tau$ to reach the temperature $373 \mathrm{~K}$ is practically independent of the injectivity of the well. For mass contents $C_{m}$ of the prepared mixture of $0.5,0.6,0.7$ this time interval is 25,15 , 10 hours, respectively (Fig. 1).

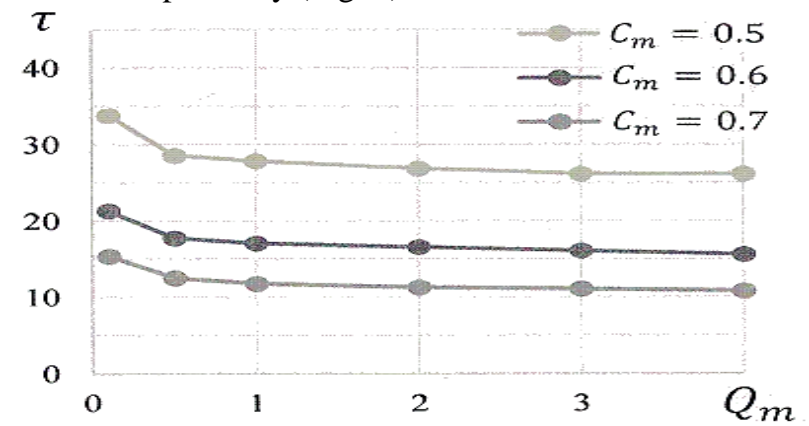

Fig. 1. Time of reaching a temperature of $373 \mathrm{~K}$ in hours depending on the mass flow rate of the binary mixture in tons per day per $1 \mathrm{~m}$ of the formation

At a fixed flow rate $Q_{\mathrm{m}} / H$ of the binary mixture $4 t /$ day per $1 \mathrm{~m}$ of the formation, the characteristic heating zone and the maximum temperature in the formation depend on the mass content. For $C_{m}=0.5$, these values are $10 \mathrm{~m}$ and $390 \mathrm{~K}$, and for $C_{m}=0.7$, they are $5 \mathrm{~m}$ and $420 \mathrm{~K}$ respectively (Fig. 2).

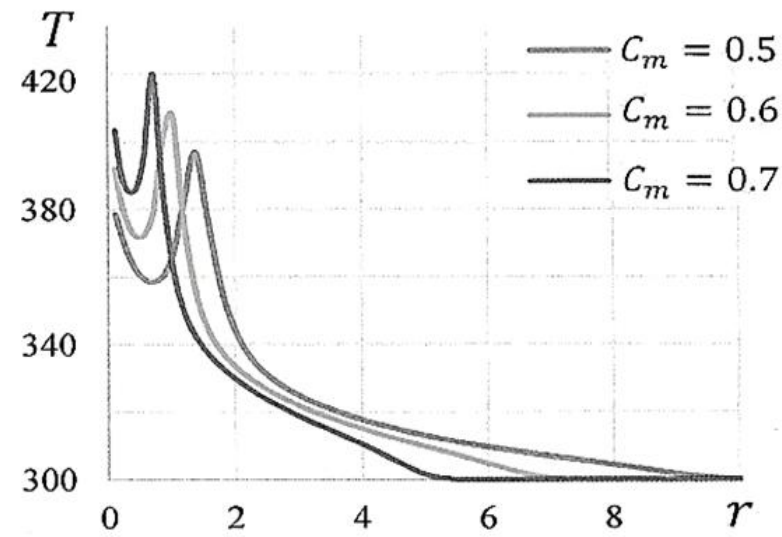

Fig. 2. Temperature distribution in Kelvin after the end of the chemical reaction. The consumption of components of a binary mixture is 4 tons per day per $1 \mathrm{~m}$ layer.

The temperature distribution in the formation at the time of the end of the reaction is non monotonic and has a maximum at some distance from the well.

\section{CONCLUSION}

A mathematical model for feeding a reacting binary mixture into a reservoir was proposed. It has been established that less concentrated binary mixtures are preferred for heating the formation.

\section{REFERENCES}

1. V. Morenov, E. Leusheva, Energy delivery at oil and gas wells construction in regions with harsh climate, International Journal of Engineering, 29(2), 274-279 (2016).

2. S. Deliya, M. Golenkin, A. Byakov, Treatment of bottom hole zones of production wells with oil-in-water emulsions to restrict breakthrough gas production in Yuri Korchagin field, Society of Petroleum Engineers, https://doi.org/10.2118/171246-MS (2014).

3. R. B. Jackson, The integrity of oil and gas wells, Proceedings of National Academy of Sciencies, 111(30), 10902-10903, https://doi.org/10.1073/pnas.1410786111 (2014).

4. V. Morenov, E. Leusheva, A. Martel, Investigation of the fractional composition effect of the carbonate weighting agents on the rheology of the clayless drilling mud, International Journal of Engineering, 31(7), 1152-1158 (2018)

5. Y. N. Sheng, Zh. Guan, Sh. Liu, K. Jiang, H. Feng, Influence of drilling fluid density on deep-water well structure design, International Journal of Petroleum Science and Technology, 10(1), 8-20 (2016).

6. J. H. Vera, G. Wilczek-Vera, Classical thermodynamics of fluid systems: Principles and Applications. CRC Press (Taylor \& Francis). ISBN: 9781315399041 (2016).

7. Sh. Jia, C.Wen, F. Deng, Ch. Yan, Zh. Xiao, Coupled THM modeling of wellbore stability with drilling unloading, fluid flow, and therma effects considered, Mathematical Problems in Engineering, https://doi.org/10.1155/2019/5481098 (2019).

8. Drilling of offshore oil wells. Retrieved from: http://www.eniscuola.net/en/argomento/oil/extraction-and-uses/drillin g-of-onshore-oil-wells/

9. B. Singh, Offshore well drilling: general overview. Retrieved from: https://www.marineinsight.com/offshore/offshore-well-drilling-a-gene ral-overview/ (2019).

10. Bureau of Ocean Energy Management, The offshore petroleum industry in the Gulf of Mexico. Retrieved from: https://www.boem.gov/sites/default/files/boem-education/BOEM-Ed ucation-Images-and-Resources/TheOffshorePetroleumIndustryOrgani zationalScheme.pdf (2012).

11. M. Christou, M. Konstantinidou, Safety of offshore oil and gas operations: lessons from past accident analysis, JRC Scientific and Policy Reports. Retrieved from: https://publications.jrc.ec.europa.eu/repository/bitstream/JRC77767/o ffshore-accident-analysis-draft-final-report-dec-2012-rev6-online.pdf (2012).

12. V. Morenov, E. Leusheva, Development of drilling mud solution for drilling in hard rocks, International Journal of Engineering, 30(4), 620-626 (2017).

13. S. P. Gupta, S. P Trushenski, Micellar flooding-compositional effects on oil displacement, Society of Petrol Engineers Journal, 14(7), 116-128 (1979)

14. F. G. Helfferich, Theory of multicomponent, multiphase displacement in porous media, Society of Petroleum Engineers Journal, 21(1), 51-62 (1981).

15. R. M. Sadeq, I. Abdelraziq, S. A. J. Mohammed, O. Bilous, The behaviour of sound absorption coefficient for binary mixture nitroethane-isooctane above critical temperature and concentration, AIP Advances, 8(11), https://doi.org/10.1063/1.5044523 (2018).

16. V. Vershinin, K. Fedorov, A. Lishchuk, Mechanisms of thermal-pressure induced impact of binary mixture reaction near wellbore, Society of Petroleum Engineers Journal, https://doi.org/10.2118/182048-MS (2016).

17. L. D. Thanh, R. Sprik, Streaming potential measurements on the binary mixture triethylamine-water near the demixing phase transition, International Journal of Geophysics, https://doi.org/10.1155/2019/6067201 (2019).

18. L. Keulen, E. Mansfield, I. H. Bell, A. Spinelli, A. Guardone, Bubble-point measurements and modeling of binary mixtures of linear siloxanes, Journal of Chemical Engineering Data, 63(9), 3315-3330. https://doi.org/10.1021/acs.jced.8b00200 (2018).

19. W. E. Kline, H. S. Fogler, Dissolution of silicate minerals by hydrofluoric acid. Industrial and Engineering Chemistry Fundaments, 20(2), 151-161 (1981)

20. G. A. Zvyagin, P. M. Yuzhaninov, A. I. Dzyubenko, Issledovaniye istochnikov zagryazneniya i tekhnologiy obrabotok nagnetatel'nykh skvazhin, Neftepromyslovoye delo, 11, 114-115 (1982).

21. R. C. Helson, G. A. Pope, Phase relationships in chemical flooding. Society of Petroleum Engineers Journal, 18(5), 325-338 (1978).

22. D. O. Shah, Surface phenomena in enhanced oil recovery. New York City: Plenum Press (1981).

23. T. Takeshi, F. Jiang, K. T. Christensen, Characterization of immiscible fluid displacement processes with various capillary numbers and viscosity ratios in 3D natural sandstone, Advances in Water Resourses, 95, 3-15. https://doi.org/10.1016/j.advwatres.2016.03.005 (2016)

24. S. Skurativskyi, I. Skurativska, Solutions of the model of liquid and gas filtration in the elastic mode with dynamic filtration law, Ukrainian Journal of Physics, 64(1), 19-26, https://doi.org/10.15407/ujpe64.1.19 (2019).

25. K. S. Basniyev, I. N. Kochina, V. M. Maksimov, Underground fluid mechanics. Moscow: Nedra Press. Retrieved from: http://www.geokniga.org/bookfiles/geokniga-basniev-podzemnaya-gi dromehanika.pdf (1993).

Published By:

Blue Eyes Intelligence Engineering

\& Sciences Publication

DOI: 10.35940/ijeat.C6570.049420

Journal Website: www.ijeat.org 